\title{
Brain glucose metabolism in thalamic syndrome
}

\author{
EC LATERRE,*AG DE VOLDER, AM GOFFINET \\ From the University of Louvain Positron Tomography Laboratory, Louvain-la-Neuve, and Service de \\ Neurologie* Cliniques St Luc, Brussels, Belgium
}

SUMMARY Regional brain glucose metabolism was studied in a case of postischaemic thalamic syndrome. Despite a normal density of the thalamus on MRI and CT images, a $17 \%$ relative hypometabolism was found in the posterior thalamus on the affected side. This observation of functional anomalies in the posterior thalamic complex in case of thalamic syndrome is compatible with a deregulated processing of pain-related information at this level.

Studies of regional brain glucose metabolism in unilateral thalamic stroke have demonstrated the frequent occurrence of hypometabolic changes in cortical areas on the side of the lesion. ${ }^{12}$ The distribution of cortical dysfunction, which was attributed primarily to deafferentation (diaschisis), was consistent with the neuropsychological disturbances. None of the patients studied, however, apparently suffered from a clinical thalamic (Déjerine-Roussy) syndrome. ${ }^{3}$ As a complement to previous studies, we performed measurements of brain glucose metabolism in a patient with a typical poststroke thalamic syndrome, but without neuropsychological impairment.

\section{Case report}

The patient, a 63 year old right-handed female with a history of high blood pressure, suffered a stroke 2 years before the study, with numbness and weakness on her left side. While the initial symptoms subsided gradually, a permanent protopathic pain with excruciating episodes of exacerbation developed progressively despite medication. At the time of the metabolic studies, the chronic pain was the prominent symptom, although she had also mild sensory deficits for all modes. Apart from the emotional lability resulting from the pain, no neuropsychological disturbances were present. Magnetic resonance imaging (MRI) and $x$-ray CT investigations (shown on fig

Address for reprint requests: $\operatorname{Dr}$ A M Goffinet, 2 Chemin du Cyclotron, B 1348 Louvain-la-Neuve, Belgium.

Received 31 July 1987.

Accepted 15 September 1987 $a$ and b) disclosed the presence of a small laminar infarct at the level of the posterior putamen and posterior limb of the internal capsula on the right side, with no visible extension into the thalamus.

\section{Method}

Regional cerebral glucose metabolism (rCMRGLc) was measured by positron emission tomography (PET), using [18F]-2-deoxy-2-fluoro-D-glucose (FDG) as the tracer. The tomograph (ECAT III, one-ring), was used at a full width at half maximum (FWHM) resolution of $9 \mathrm{~mm}$. Serial tomographic slices parallel to the canthomeatal line were recorded, corrected for attenuation with an operator-defined ellipse to approximate the head's contours $(\mathrm{mu}=0.090)$, and translated into local glucose metabolic rates by using the autoradiographic model. ${ }^{45}$

\section{Results}

Two studies were performed with a two month interval, in the same conditions (resting state, supine position, eyes open, ears unplugged) and yielded similar results. By comparison with reference values measured in normal, healthy volunteers, global brain glucose utilisation was within normal limits $(47.55 \mu \mathrm{mol} / 100 \mathrm{~g} / \mathrm{min})$, and quite high and symmetrical in temporal $(50.22)$, parieto-occipital (44.04), and visual (53.97) cortical areas, as well as in the cerebellum (46.01). By contrast, there was a clear deficit in the right (32.34) versus left $(38 \cdot 14)$ thalamus (17\% asymmetry), particularly at the level of the posterior thalamic complex, as well as in the posterior tiers of the right putamen $(26 \%$ and $23 \%$ asymmetry, respectively). A typical image of the first study is shown on fig $\mathrm{c}$. 

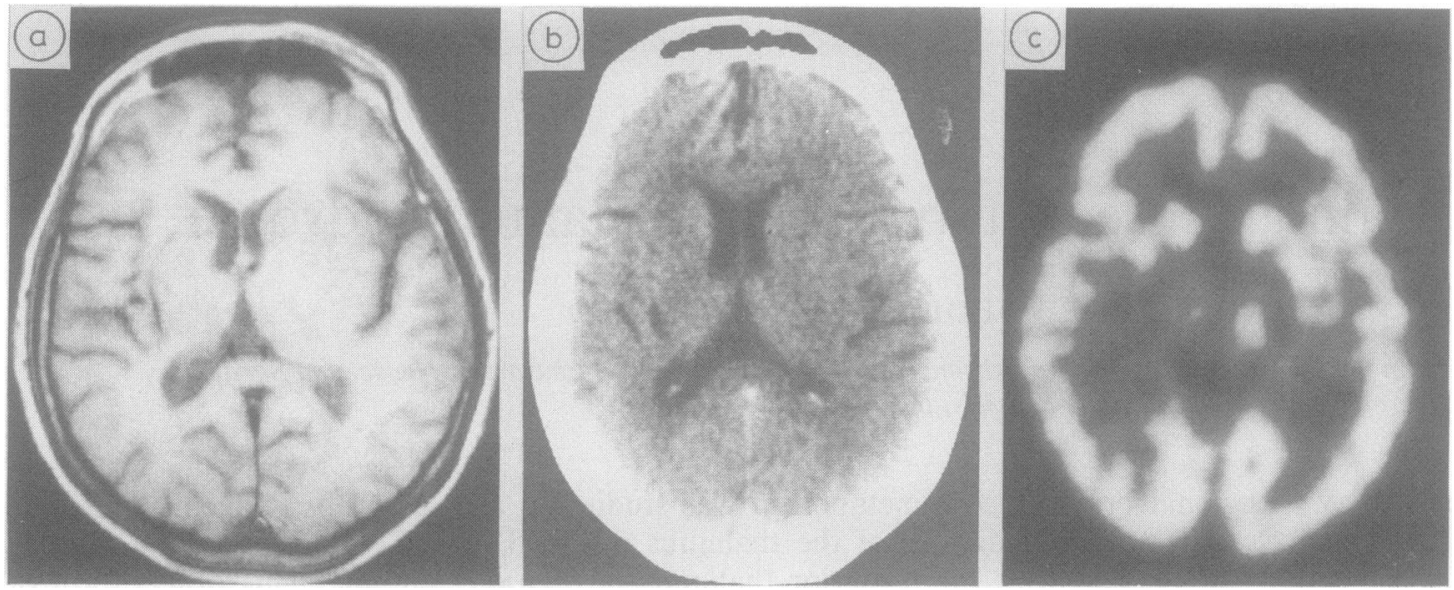

Fig MRI, T1 weighted (a), x-ray CT (b) and PET (c) images at the level of the thalami (the right side of the head is to the left). The laminar infarct in the right putamen and internal capsula is well visible with MRI and CT. A corresponding, broader zone of hypometabolism involving the right posterior thalamus, is evident on PET.

\section{Discussion}

The occurrence of a thalamic syndrome following an infarct in the internal capsula and/or adjacent structures, although uncommon, is well known. ${ }^{36}$ Our observations show that the chronic pain syndrome in this case occurred in parallel with a decrease in glucose metabolism in the posterior thalamic nuclei and that, in contrast to the cortical disturbances which frequently accompany large thalamic infarctions, ${ }^{12}$ no metabolic alterations were found in the cerebral cortex. Presumably, subtle metabolic alterations in the thalamus can be detected with PET in the absence of obvious parenchymal involvement. The method employed, however, does not allow the distinction between structural alterations undetected with MRI or CT scan, and hypometabolism secondary to deactivation, for example by interruption of corticothalamic connections.

The various hypotheses which have been proposed in order to explain the symptoms of the thalamic syndrome are generally related to two basic mechanisms (see Schott et al, ${ }^{7}$ for a recent discussion). Firstly, lesions of some thalamic nuclei, particularly in the posterior group ${ }^{8}$ could result in a loss of the physiological gate control on sensory afferents. Secondly, thalamic pain could be dependent on perturbations of thalamocortical and corticothalamic control loops. Our observation of a hypometabolic focus in the posterior thalamic complex in the absence of any cortical involvement, lends some support to the first of these hypotheses.

\section{References}

1 Baron JC, D'Antona R, Pantano P, et al. Effects of thalamic stroke on energy metabolism of the cerebral cortex. A positron tomography study in man. Brain 1986;109:1243-59.

2 Baron JC, D'Antona R, Serdaru M, et al. Hypométabolisme cortical après lésion thalamique chezồ. l'homme: Etude par la tomographie à positons. Rev. $\stackrel{\rightleftharpoons}{\infty}$ Neurol. (Paris), 1986;142:465-74.

3 Adams RD, Victor M. Principles of Neurology. 3rd ed., New York: McGraw-Hill, 1985, 99-113.

4 Sokoloff L, Reivich M, Kennedy C, et al. The (C-14) deoxyglucose method for the measurement of local cerebral glucose utilization: theory, procedure and normal values in the conscious and anesthetized albino rat. J. Neurochem 1977;28:897-916.

5 Phelps ME, Huang SC, Hoffman EJ, et al. Tomographic measurement of local cerebral glucose metabolic rate in humans with [F-18]2-Fluoro-2-deoxy-D-Glucose: validation of method. Ann. Neurol. 1979;6:371-88.

6 Cambier J. Le syndrome de Déjerine-Roussy. Rev. Neurol. (Paris), 1982;138:979-88.

7 Schott B, Laurent B, Mauguière F. Les douleurs thalamiques: étude critique de 43 cas. Rev. Neurol. (Paris), 1986;142:308-15.

8 Brodal A. Neurological Anatomy, 3rd Ed., Oxford: Oxford University Press (1981), 121. 